\title{
Portfolio Management on an Emerging Market: Dynamic Strategy or Passive Strategy?
}

\author{
Pourakin Djarius Dieudonné BAMA \\ Correspondence: Assistant Professor, Department of Management, Ouaga II University, Faculty of Economics and \\ Management Science, Ouagadougou - Burkina Faso, P.O. Box 343, Ouagadougou, Burkina Faso.
}

Received: June 2, 2020

doi:10.11114/bms.v6i2.4916
Accepted: June 27, 2020

Online Published: June 28, 2020

URL: https://doi.org/10.11114/bms.v6i2.4916

\begin{abstract}
At first glance, the portfolio management strategy seems like a resolved question, but practitioners continue to perform poorly on the stock markets. This paper highlights the portfolio management in the specific case of the West African regional stock exchange, regarding two management strategies. These are dynamic strategy and passive strategy. Within this framework, we will compare an investor who is constantly betting on price fluctuations with another who is betting on dividends. Its originality lies in the approach that is used. Through a simulation methodology based on real market data, the main results indicate that an emerging market is a savings market more than it is a speculation market. Besides, other results indicate that, one can predict on the West African regional stock exchange tomorrow's prices from today's prices. This does not mean that investors are making good predictions because the predictability of prices is due to the absence of changes in asset prices on the market. We draw the conclusion that it is difficult for one speculator to outperform the other. A rational investor would benefit from anticipating the distribution of dividends rather than focusing on price fluctuations. Consequently, the buy and hold strategy is therefore the best to be rewarded in an emerging market. Nonetheless, this practice can lead to a decline in liquidity.
\end{abstract}

Keywords: passive strategy, dynamic strategy, portfolio management, volatility, emerging market

\section{Introduction}

At first glance, the portfolio management strategy may appear to be a question that was resolved with Markowitz's early work in 1952, but practitioners continue to perform poorly on the stock markets. The possibility for an investor to obtain economic benefits from their investments depends on the choices they make in order to correctly anticipate the prices of the shares and the dividends to be distributed. The starting point for this choice is the mean-variance model, supplemented later by the Capital Asset Pricing Model (Sharpe, 1964), the efficiency of the financial markets (Fama, 1970) and the three-factor model (Fama and French, 1992). However, not everyone is given the ability to make such a choice, since not all of them are necessarily intelligent (Thaler and Sunstein, 2009). Amongst themselves, they very often imitate each other, are sometimes wrong and make the same mistakes about the future (Tvesky and Kahneman, 1974; Lakonishok et al, 1992; De Winne and D'Hondt, 2017). Therefore we can assume that investors do not all have the capacity to observe the characteristics of assets, not only because of cognitive limits but also because of the volatility of the financial markets which they are subject to. Despite their volatility, emerging markets represent good investment opportunities because of their potential for high profitability and their relatively low correlation with developed markets (Boyer et al, 1997). Nevertheless, investors are not rewarded for the risk they take on certain emerging markets, such as the regional stock market (Essingone and Diallo, 2019). This therefore raises the issue of the strategy that an investor must adopt in an emerging market to be rewarded. If standard portfolio management models (Markowitz, 1959; Sharpe, 1964; Fama and French, 1992) seem to provide a general framework for the analysis and selection of financial assets, these models are based on a simple principle. This is about knowing how to diversify one's asset portfolio. However, diversifying is only possible on developed stock markets with multiple listed companies, compared to emerging markets where there are fewer listed companies. One legitimate question that we should ask is whether one can get economic benefits in an emerging market where information processing capacity is limited. If this question is answered as to the best styles or strategies for asset allocation in developed markets (Sharpe, 1992; Jeffery, 2004; Aaron et al. 2005), very few research studies have questioned the better asset allocation strategy in emerging markets, let alone on the West African regional stock exchange. The objective of this article is to investigate on the investment strategy in an emerging market. It contributes to enriching the literature on the subject and to responding to 
the issue of portfolio management in emerging markets. Therefore, its originality lies in the approach that is used. This is a simulation which uses actual market data. This approach consists of a simulation in which agents are distinguished only by their investment strategy. If we assume that investors are not remunerated for the risk they take in an emerging market, we can therefore imagine that those who bought shares are forced to keep them for a long period in order to wait for dividends. The rest of the article is organized as follows: Section 1 is devoted to a literature review. Section 2 develops an approach using a simulation methodology. The results of this approach are presented in section 3 and discussed in section 4 .

\section{The Literature Review}

The literature on the portfolio management strategy is mainly developed by econometric models where the idea is to choose the determinants or the development of prices. In this layout, investors need to seek the right information in order to make good decisions, depending on how efficient the market is. However, investors' behavior is often automatic, senseless, and habitual, and are the cause of the irregularities observed on the financial markets (Shiffrin and Schneider, 1977; Langer, 1989; Louis and Sutton, 1991; Bargh and Chartrand, 1999). Subsequently, the portfolio management strategy is no longer solely dependent on the state of market efficiency, but also dependent on the investors' attitudes and behavior. In this sense, the behavioral portfolio theory developed by Shefrin and Statman (2000) and the underlying management models provide an explanatory framework for investment and portfolio management choices. Before pursuing with the development of these models, it is worth recalling the concept of the emerging market and the theoretical foundations of portfolio management, which is the theoretical underpinning of investors' strategic behavior.

\subsection{The Concept of Emerging Markets}

The word "emerging" is a concept. There is therefore no universally recognized and unanimous definition of emerging stock markets. This concept covers several notions. It sometimes refers to a stock market which is starting a process of growth and modernization, making it more attractive to investors. The literature often characterizes emerging stock markets by their small size, their small market capitalization, their regulation and the nature of the investors (Stiglitz and Weiss, 1981). In emerging markets, the capacity of data collection and information processing is limited due to inconsistency in the dissemination of information by public and market authorities. The prices of shares in such markets cannot reflect all of the information available. Therefore, this makes it difficult for investors to interpret the information correctly. Most studies tend to show that emerging markets are less efficient. Indeed, it seems that emerging stock markets in African countries are less efficient than their counterparts in developed countries (Bekaert and Harvey, 1995). Studies already conducted showed that the efficiency hypothesis is rejected in almost all of the emerging African stock markets (Mlambo and Biekpe, 2007; Enowbi et al, 2010). However, because of the fact that empirical evidence validate the efficiency hypothesis and the volatility of the stock markets, the results are thwarted (Kryzanowski et al, 1997; Goh and Kok, 2001; Stachowak, 2004). Volatility is linked to the excess trading by over-confident investors, errors in judgment and heuristic simplifications and the publication of financial ratings (Tversky and Kahneman, 1974; Shiller, 2000; Hirshleifer, 2001; Orléan, 2001; Bayoudh et al, 2008; Petit, 2011). It is important to note it takes time for the market to become efficient, because convergence towards efficiency is not immediate (Chordia and Subrahmanyam, 2005). This implies that any investor must make sure that the state of market is efficient before making judicious choices (efficient, inefficient) and it is only on this condition that they should choose their management strategy portfolio.

\subsection{Portfolio Management: Theoretical Foundations}

The medium-variance approach and Markowitz's works (1952) on portfolio diversification have made decision-making operational in the area of portfolio selection. In this approach, the profitability of a share or a portfolio is considered as a relative measure of the total remuneration of its holder. This remuneration is assessed on a given date and for a given holding period. It therefore takes into account the capital gain or loss (capital gain or loss) from this holding and the real income (dividends) paid over the period. Indeed, when an investor buys a share $(i)$ at a time $(\mathrm{t})$ and decides to resell it in $(t+1)$, the anticipated income $\left(r_{t}\right)$ that they are entitled to is equal to $\left(d_{t+1}+p_{t+1}-p_{t}\right) / p_{t}[\mathbf{1}]$, with (p_t) being the price of the share in period $(t)$ and $\left(p_{t+1}\right)$ being the price at that time $(t+1)$ as the investor anticipates taking into consideration the information they have on the exchange rate. The quantity $\left[\left(p_{t+1}\right)-\left(p_{t}\right)\right] /\left(p_{t}\right)$ is interpreted as being the profitability caused by price fluctuations or the anticipated capital gain. This profitability is the remuneration provided to the investor, who sells their share at a higher price than they bought it. The term $\left(d_{t+1} / p_{t}\right)$ is the profitability due to the dividend distributed at the time $(t+1)$. In an uncertain universe, the interpretation of 
profitability $\left(r_{t}\right)$ only makes sense if the risk $(\delta)$ measured by $\sqrt{\frac{1}{n} \sum_{1}^{n} r_{i}^{2}-\bar{r}^{2}} \quad$ [2] associated to it is known. We consider $\left(r_{i}\right)$ as a random variable which mean $(\bar{r})$ is estimated.

Profitability and risk are the basic elements of individual choices on which investors must build their anticipation according to the principle of economic rationality. According to this principle, the individual has a perfect knowledge of their environment. They are therefore able to anticipate the future due to their cognitive abilities. However, certain studies question the hypothesis of rationality (Simon, 1955). This author believes that other hypotheses of rationalities were likely to provide a more realistic representation of individual behavior. The idea is to show that the investor often has only incomplete information. Under these conditions, Simon (1955) proposes to substitute the concept of maximization with that of satisfaction. Which is to say that, according to Simon, the investor does not seek to obtain better gains, but satisfactory gains.

Unlike the rational choice model, the limited rationality model insists that the individual has a certain representation of their environment. Consequently, they will never take the optimal solution, but a solution which seems satisfactory to them. Because the individual relies on reasons which seem sufficiently strong to them and thus adopts the behavior which allows them to reach their objective - within the limits of their knowledge (Gouin and Harguindéguy, 2009; Boudon, 1998). In many situations, investors do not behave rationally (Bouattour and Miloudi, 2016). In this sense, the theory of perspectives indicates that investors are very attentive to variations in wealth (gains or losses) but more concerned with losses than to the realization of gains (Tversky and Kahneman, 1974). Besides, investors generally tend to classify shares in different mental compartments according to the situation of the shares on the market (Thaler, 1980). When the price of a share is low compared to its purchase price, an investor prefers to keep it than to sell it. This implies that the decision whether or not to intervene in the market depends on the price of the share compared to its acquisition price. This classification appears to be close to the model of Shefrin and Statman, (2000). These authors indicate that investors tend to classify their portfolios in a pyramidal shape. One layer of portfolios is made up of less risky shares, like bonds for example, and other layers made up of shares with very high profitability, but very risky. However, it should be noted that this classification depends on how the investor feels, because there is no guarantee that the portfolio of risky shares will be profitable. Very often, investors make choices based on simplified calculations or sometimes on their own experience (Hua and Wang, 2018). These authors show that in the face of risk, the choice of an investor depends on the cost and profitability that they expects. For others, the choice depends on preferences for the present "impulsive decision" or for the future "delayed decision" (Loewenstein, 2001). This means that the investor can make a choice for the present or for the future. When they prefer small and immediate rewards, they bet for the present - otherwise, they will bet for the future when they prefer large and delayed rewards.

\subsection{The Underlying Methods}

From the standard portfolio management model (Markowitz, 1952, 1959) to the three-factor model (Fama and French, 1992), going through the market model - the Capital Asset Pricing Model (Sharpe, 1964) and that of the financial market efficiency (Fama, 1970) - The analysis of asset profitability is made in a logic of explanation. According to the market model, the relationship between the profitability of a share $\left(r_{i}\right)$ and the profitability of the market $\left(r_{m}\right)$ can be determined by: $\alpha_{i}+\beta_{i} r_{m}+\varepsilon_{i}$ [3] in which $\left(\beta_{i}\right)$ measures how the returns of shares $(i)$ evolve compared to the returns of the most representative assets on the market. In other words, this coefficient expresses the susceptibility of a share compared to the market as a whole. Epsilon $\left(\varepsilon_{i}\right)$ is a residue which is not explained by alpha $\left(\alpha_{i}\right)$ or the profitability of the market, i.e. $\left(r_{m}\right)$. It is supposed that $\left(\varepsilon_{-} i\right)$ is a random variable normally distributed and independent of $\left(r_{m}\right)$. This means that $\operatorname{Cov}\left(r_{m}, \varepsilon_{i}\right)$ and the mathematical expectation of the residuals are all zero. The parameters $\left(\alpha_{i}\right)$ and $\left(\beta_{i}\right)$ are the result of regression calculation. Equation (3) is used to predict the explained variable with respect to the explanatory variable. The degree of influence of $\left(r_{m}\right)$ on $\left(r_{i}\right)$ depends on the importance of $\left(\beta_{i}\right)$. We assume that the variations of $\left(r_{i}\right)$ are random and have two (2) causes. It is about market influence (exogenous cause) and good or bad management (endogenous cause) of the company. The variability in profitability $\left(r_{i}\right)$ constitutes a risk. This risk is interpreted as the total risk of the share $(i)$ measured by this relation: $\beta_{i}{ }^{2} \delta_{m}{ }^{2}+\delta_{\varepsilon i}{ }^{2}$ [4]. Quantities $\left(\beta_{i}{ }^{2} \delta_{m}{ }^{2}\right)$ and $\left(\delta_{\varepsilon i}{ }^{2}\right)$ respectively measure the systematic variance and the specific variance corresponding respectively to unanticipated macroeconomic events and to specific events affecting the company. Very often, we use the coefficient of determination labelled $\left(r^{2}\right)$ to measure the non-systematic risk of a value compared to the market as a whole. Under these conditions, if $\left(r^{2}\right)$ is close to 1 , it means that the correlation with the market is important. In this case, the non-systematic risk is low and the $\left(1-r^{2}\right)$ tends towards zero. If, on the other hand, this quantity is higher for (x) value than for (y) value (y), this means the $(\mathrm{x})$ value is more independent of the market than $(\mathrm{y})$ value. But the risk of a portfolio can be reduced by diversification.

Let's assume a portfolio of (n) shares. The values of $\left(\varepsilon_{i}\right)$ are independent of each other for the different shares. From this 
point of view, the specific risk $\left(\delta_{\varepsilon p}\right)$ of the $(p)$ portfolio is assessed by: $\sqrt{1 / n^{2} \sum_{i} \delta_{\varepsilon i}^{2}}$ [5]. If $\left(\bar{\delta}_{\varepsilon}^{2}\right)$ designates the average value of the individual risks of each share in the portfolio $(p)$, the specific risk becomes $\left(\bar{\delta}_{\varepsilon}^{2} / n\right)$. Theoretically, this quantity tends towards 0 if $(n) t$ tends towards infinity or becomes large. This means that the specific risk decreases as the number of shares making up the portfolio increases. An investor would benefit from adding shares to their portfolio in order to completely eliminate or reduce the risk of the portfolio. However, adding more shares implies an increase in risk. From this point of view, the net effect of adding more share to the portfolio could be more of an increase in risk than a decrease. It is therefore necessary to find the optimal combination.

As one can see, the market model based on simple regression is a tool for understanding the behavior of a share. However, the three-factor model relies on a multiple regression of three variables said to be fundamental (size, book-to-sales ratio value / market value) to explain the profitability of the shares. This model estimates that the differential between the profitability of a risky share $\left(r_{i}\right)$ and that of a non-risky share $\left(r_{f}\right)$ at time $(t)$ can be evaluated by: $\alpha_{i}+\beta_{i}\left(r_{m, t}-\right.$ $\left.r_{f, t}\right)+s_{i} S m b_{i}+h_{i} H m l_{i}$ [6]. In this relation, $\left(r_{i, t}-r_{f, t}\right)$ represents the differential of profitability observed at time $(t)$. $\left(S m b_{i}\right)$ represents the profitability of the share $(i)$ resulting from the difference between the profitability of the shares of small stock market capitalization and the profitability of shares of large stock market capitalization. Finally, $\left(H m l_{i}\right)$ indicates the profitability of the share $(i)$ resulting from the difference between the profitability of the shares with a high ratio (book value/market value) and that of a low ratio (book value/Market value). The parameters $\left(\beta_{i}, s_{i}, h_{i}\right)$ are coefficients that need to be estimated. We can see that the three-factor model takes into account the market risk and the risk linked to size as well as that attributed to the ratio (book value of equity capital/ market value). From this point of view, it makes the important variables of the investment decision even more explicit than the Capital Asset Pricing Model which measures the differential between the profitability of a risky share $\left(r_{i}\right)$ and that of a non-risky share $\left(r_{f}\right)$ at time $(t)$ only by: $\beta_{i}\left(r_{m}-r_{f}\right)[7]$.

The models we have just mentioned have a common purpose. What investors need to do is to make a financial choice or take a rational decision with expected random profitability. These models offer a variety of portfolio management and selection styles based on decision making. This choice often involves implicit costs such as the cost of finding information, the cost of continued presence on the market and the cost of processing important data. However, some investors may proceed in stages or decide to opt for an "ad hoc" selection of shares by favoring certain shares according to criteria which are personal to them (Aaron et al, 2005).

\subsection{The Stages of Portfolio Management}

We can keep several stages of decisions. Mathis (2002) distinguishes three: strategic, tactical and selective. The first consists in choosing the benchmark segment of the market in which you want to invest. The second is about the specification of the objectives, and the last is the choice itself. As for Aaron et al (2005), they have developed six styles. Table 1 shows the six styles which they developed.

Table 1. Definition of theoretical management styles

\begin{tabular}{|l|l|c|c|}
\hline Styles & \multicolumn{1}{|c|}{ Conditions for the selection of shares } & Indication & Objective \\
\hline Index & Affiliation to an index & Market index & Replicate \\
\hline Quantitative & Affiliation to an index & Market index & Outperform \\
\hline Sector-specific & Sector and macro-economic cycle & Sector-specific index & Outperform \\
\hline Stock-picking & Fundamental data & No & Compare \\
\hline Growth & Fundamental data and steady profit growth & No & Compare \\
\hline Value & $\begin{array}{l}\text { Fundamental data and discounted values } \\
\text { with a high potential to increase }\end{array}$ & No & Compare \\
\hline $\begin{array}{l}\text { Source : Aaron, C., Bilon, I., Galanti, S., \& Tadjeddine, Y. « Do portfolio management styles exist »? } \\
\text { Financial economy review (2005) (table 1) }\end{array}$
\end{tabular}

The "index" style is the one that prioritizes shares belonging to an index, then to their fundamental characteristics. By choosing this style, the objective is to replicate the market index. In contrast, the "quantitative" style differs from the index style on the nature of the commitment to the benchmark. In these conditions, the investor no longer aims at replicating but rather at doing better than the benchmark. The "sector-specific" style focuses on a sector-specific selection to which the values belong, but while taking into account their performance. In the three (3) styles, the selection is made on the basis of an index (market or sector) with the aim of beating the market or outperforming the portfolio (s). For the case "stock picking" the investor speculates and prioritizes the shares according to their fundamental data as well as their future values. The "growth" style adheres to this vision, but is more oriented towards 
companies with a recognized activity and steady revenue. Finally, the "value" style is close to the last two (2), but the choice is directed towards the shares of companies for which a significant rise in prices is expected.

When an investor chooses a style, they believes that it will allow them to build a portfolio which average - variance combination is greater than that of the market portfolio (Mathis, 2002). Thus, the investor's goal of beating the market implies that they are able to anticipate the distribution of future returns on the basis of econometric models. In that sense, the condition of normality is required before certain econometric tests can be carried out. For the investor, such a conditionality poses practical difficulties for the construction and optimal management of their portfolio - due to the instability of risk factors which favor abnormal distributions of stock market data.

\subsection{The Predictable Normality of Profitability}

It is important to note that the distribution of returns over time is generally assumed to follow a normal law, verified from econometric tests. Statistically, we consider that a distribution is symmetrical, if the observations are also dispersed on each side of the central value, otherwise it is considered asymmetrical. Several tests are used to highlight normality. The most common is the Bera - Jarque test. However, it should be noted that a lot of empirical work has pointed out that normality is not particularly verified for financial data because of the characteristics of the financial markets from which they originate (Lecourt, 2000; Hatemi, 2002; Kyrtsou and Terraza, 2003; Bourachnikova, 2009). Studies confirm this in the specific case of stock market data from the regional stock market (Bayala, 2002; N'dong, 2007; N'dri, 2007; Bayala and Bama, 2019). This assumes that most economic series follow a non-stationary process. Stationarity and predictability are closely linked. A random variable is said to be predictable when it is stationary. Several models, such as those from the "garch" family are used to make forecasts or anticipations on the volatility of the distribution of returns. However, the implementation of these models encountered practical difficulties due to the requirement of the maximum likelihood method used for the estimation. The most common test for stationarity is the augmented Dickey-Fuller unit root test.

As a general framework for analysis, the standard portfolio management model (Markowitz, 1959) and its extension (Sharpe, 1964; Fama and French, 1992), several studies on the stocks portfolio's management style have been carried out on developed countries' stock markets (Sharpe, 1992; Jeffery, 2004; Aaron et al. 2005). However, few research studies have questioned the best asset allocation strategy in emerging markets, let alone the West African regional stock market. Research covering this market, which goes in the direction of portfolio management, has focused on market efficiency and the volatility of stock prices (Christol, 1996; N'dong, 2007), the predictability of profits (N'dri , 2007), asset valuation models (Soumare et al, 2013). Recent research has also questioned the depth and liquidity of the market (Bayala and Bama, 2019), investor behavior (Bama and Bayala, 2019), profitability and risk (Essingone and Diallo, 2019), investor inertia (Bama, 2019).

These models are undoubtedly the most used by the financial community both for the estimation of profitability, the development of investment strategies and for the management of portfolios. There is therefore no more need to demonstrate the legitimacy of these models as a point of reference for decision-making. The standard model initially developed by Markowitz, taken over and completed by Sharpe lead to the balance model between risk and profitability, deals with the attitude an investor should have towards the risk to which they are exposed to. Certainly, these models have an explanatory and predictive capacity but, do not have the absolute power to determine the best strategy which offers an economic advantage to an investor. Most models are parametric and require an estimation of the parameters. However, in practice, investors face problems of data (missing or abnormally distributed). This implies that the use of the usual models applied in emerging markets may bias the analyses. A standard methodology such as simulation can be a methodological alternative to solve this problem.

\section{Methodological Proposition Through a Simulation}

Unlike traditional models where volatility is demonstrated by econometric tests, we propose to simply study it by a coefficient of variation. Our approach is based on a method of simulation methodology. It remains one of the original research methods likely to explain the best strategy to adopt in the context of emerging markets. The advantage of the simulation is that it enables to formalize theoretical propositions coming from observations (Davis et al, 2007). Another advantage of the simulation is that it also explains a phenomenon and treats it on the basis of small-scale data. This implies that the simulation can be used for multiple purposes. If this method proves to be interesting, it will require a modeling process which begins with the identification of the problem.

\subsection{The Problem}

The evaluation of profitability, as indicated above, seems to be theoretically questionable when we analyze the two components of the profitability of a share. Indeed, the profitability $\left(r_{i}\right)$ of a share $(i)$ results from two components of the same signs if there is a surplus value $\left(p_{t+1}>p_{t}\right)$, and of opposite signals in case of capital loss, meaning that 
$\left(p_{t+1}<p_{t}\right)$. As a result, $\left(r_{i}\right)$ is not necessarily posivitive - even if there is a distribution of dividends because a capital loss could cancel this income. The profitability $\left(r_{i}\right)$ is measured as if at time $(t+1)$, the investor receives the dividend and immediately sells their share at the same date. If the investor doesn't manage to sell their share at the date $(t+1)$ because of lack of liquidity, it is very likely that the price of the share will drop significantly the next day. So, the profitability of the share evaluated by the equation [1] can decrease significantly, or even be null or negative. This idea offers two options. A "dynamic or active strategy" and a "buy and hold strategy". The former consists in betting on the fluctuation of market prices and the latter consists in betting on the dividends. The best strategy is the one which offers the best possible profitability for a given level of risk. If the investor anticipates on the period of payment of high dividends as compared to less important variations in the price of shares, they will prefer to hold their share and expect dividends only. Is this a good strategy? Based on actual market data, our goal will be to compare the two strategies.

\subsection{The Data}

Data have been provided by the West African regional stock exchange authorities. They concern all the listed companies since the creation of the Regional Stock Exchange in 1998 up until December 31, 2014. As of today, there are 47 listed companies to 36 at creation, meaning 11 companies have been added since the date of creation of the West African regional stock exchange. Analysis of the data that have been submitted to us reveals that several of them have not paid dividends over a long period. We have therefore decided to dismiss these companies so as to finally keep the companies that have paid dividends once at least over every 2 years. Under these conditions 20 companies have been retained. These data are supplemented by the introductory and the daily prices of these companies. To make them homogenous, we have successively divided each dividend by the introductory rate. We then get 260 observations varying between 1314 and 2361 for the daily rate for all the companies combined. So we have two types of samples.

\subsection{Model and Simulation}

An investor who anticipates the payments of high dividends during this period, as compared to less significant variations of the price of the share $(i)$ will prefer to hold their share and expect dividends only, for a given level of risk $(\delta)$. So, let's consider for example, a market of share $(i)$ where two (2) agents are distinguished by their strategies. One agent is active and the other is passive during a period going from $(t)$ to $(t+n)$ and whose strategies are respectively represented by $\left(S_{j}\right)$ and $\left(S_{k}\right)$. Let's take for example the price of the share $(i)$ at the date $0,1, \ldots,(n-$ $1), n$. Let's suppose that the active investor intervenes on a daily basis on the market and that it is possible to sell at a higher price and buy the same share at a lower price in the same day. We can therefore evaluate the profitability $r\left(S_{j}\right)$ by: $\frac{1}{n} \sum p_{t+1}-p_{t} / p_{t}[\mathbf{8}]$. In this case, both the active agent who speculates and the passive agent who holds their share are entitled to the dividends. If the company makes profit, the agent who has a share will receive an infinite amount of dividends whose profitability $r\left(S_{k}\right)$ can be estimated by the following relation: $\frac{1}{n p_{0}} \sum d_{t}$ [9].

We will ignore the transaction costs and income tax. Thus, for an equal risk, we can note that the profitability stemming from the passive strategy is dependent on the anticipated $(d)$ dividends $\left(S_{k}\right)=f(d)$. The profitability resulting from the other strategy depends on the variation in the prices of the share $r\left(S_{j}\right)=f(\Delta p)$. In these conditions, we can note that the agents prefers $\left(S_{j}\right)$ to $\left(S_{k}\right)$, if and only if $r\left(S_{j}\right)>r\left(S_{k}\right)$. Otherwise, we will go further by using the coefficients of the profitability variation. Using profitability solely only makes sense if it is calculated from a sample of the same size. Since this condition is not met, we will use a relative measure in addition, namely the dispersion of the risk measured by the coefficient of the variation indicated by: $\operatorname{Cv}(r S)=s / r(S)$ [10]. In this relation, $s=$ $\sum_{i=1}^{n}\left(r_{i}-r(S)\right)^{2} / n-1$ is the estimated risk indicating the degree of the homogeneity of the distribution of the profitability associated with each strategy and $r(S)$ is the average profitability, meaning that it is a constant. According to Lapointe (2011, p. 256), a coefficient with a variation which is less than 0.15 indicates a good homogeneity, a weak dispersion, thus a small variation. If it is between 0.16 and 0.3 , the homogeneity is said to be medium and very low if it is greater than 0.3 .

However, it should be remembered that studies have shown that the overall profitability of the regional stock market is negative (Essingone and Diallo, 2019). We can therefore expect the coefficients of the estimated variation to be negative. To solve this problem, we will turn them into absolute values. The absolute value of a number is considered to be its distance from zero. From this point of view, the coefficients of variation are considered to be the volatility of profitability in relation to zero. In that sense, the profitability will be said to be less volatile, if their coefficient of variation tends towards zero - otherwise, they will be considered more volatile. So, we will suppose that strategy $\left(S_{j}\right)$ 
will be preferred to strategy $\left(S_{k}\right)$, if $\left|C v\left(r S_{j}\right)\right|<\left|C v\left(r S_{k}\right)\right|$. Otherwise this means that the profitability distribution of the active strategies deviates relatively less from their center (zero) than that of the passive strategy. They are said to be less volatile, therefore more homogeneous. Ultimately we will retain $S_{j}$, if the following two conditions are met.

$$
S_{j} \geqslant S_{k} \quad \text { if } \begin{cases}r\left(S_{j}\right)-r\left(S_{k}\right) & >0 \\ \operatorname{Cv}\left(r S_{j}\right)-\operatorname{Cv}\left(r S_{k}\right) & <0\end{cases}
$$

We should remember that in a universe of $(n)$ shares, each agent has the possibility to make up a portfolio containing all the shares on the market. We respectively call the portfolios resulting from each strategy, dynamic portfolio and passive portfolio. However, as part of the predictability study, we use the Dickey-Fuller unit root test, shown by the following relation: $\Delta r_{i, t}=\alpha+\varphi r_{i, t-1}+\varepsilon_{i, t}$ [12]. In this relation, $\left(\Delta r_{i, t}\right)$ represents the change in the profitability of the stocks $(i)$ regarding two periods $\left(r_{i, t-1}\right)$ the past profitability; $\left(\varepsilon_{i, t}\right)$ residues and $(\varphi)$ a coefficient to estimate. It should be highlighted that a variable is predictable when it is stationary over time. From this standpoint, the predictability of returns amounts to formulating two alternative hypotheses $\left(H_{0}\right.$ and $\left.H_{1}\right)$ namely $H_{0}:(\varphi)=0$ and $H_{1}:(\varphi) \neq 0$. If $\varphi=0$, we are in a non-stationary process and if $\varphi<0$, we are in a stationary process.

\section{Results}

In this section we are presenting the results according to the proposed simulation. These results include the individual returns of the shares and the volatility of the portfolio in dynamic and passive strategies. In this section we will also deal with whether the price of the shares studied are stationary or not.

\subsection{The Individual Profitability of the Assets}

With the relation [1], we can assess the individual returns obtained from holding a share of an investor who expects dividends only and those of an investor who speculates. This profitability concerns an investor who bought the share of a company since its Initial Public Offering (IPO). Tables 2 and 3 respectively show the individual returns in the order of importance. This is the remuneration of a passive investor and that of an active or dynamic investor on the regional stock exchange.

Table 2. Individual returns obtained from the holding of a share

\begin{tabular}{|l|c|c|c|c|c|}
\hline Companies & CA & $\begin{array}{c}\text { Average } \\
\text { profitability }\end{array}$ & Companies & CA & $\begin{array}{c}\text { Average } \\
\text { profitability }\end{array}$ \\
\hline Shec & 30,375 & $3,5 \%$ & Boan & 20,005 & $9,9 \%$ \\
Cabc & 53,000 & $3,9 \%$ & Boab & 30,025 & $10,5 \%$ \\
Sicv & 9,995 & $6,4 \%$ & Sogc & 17,000 & $13,0 \%$ \\
Bicc & 34,000 & $6,5 \%$ & Sibc & 118,000 & $14,6 \%$ \\
Cfac & 18,000 & $7,4 \%$ & Prsc & 60,200 & $17,8 \%$ \\
Bnbc & 28,500 & $7,7 \%$ & Sphc & 10,460 & $18,8 \%$ \\
Stbc & 76,500 & $8,3 \%$ & Ttlc & 33,780 & $19,6 \%$ \\
Semc & 22,000 & $8,7 \%$ & Sdsc & 22,190 & $20,7 \%$ \\
Ciec & 17,900 & $9,2 \%$ & Sgbc & 15,790 & $21,5 \%$ \\
Sdcc & 14,500 & $9,8 \%$ & Snts & 22,000 & $30,8 \%$ \\
\hline CA: this represents the buying cost of each company's stock when it goes public. \\
\hline
\end{tabular}

Table 3. Individual profitability resulting from price fluctuations

\begin{tabular}{|l|c|c|l|c|c|}
\hline Company & Observations & Average & Company & Observations & Average \\
\hline sgbc & 1,731 & $-0,6 \%$ & bicc & 1,293 & $0,0 \%$ \\
boan & 1,304 & $-0,3 \%$ & sicv & 1,585 & $0,0 \%$ \\
cfac & 667 & $-0,2 \%$ & sphc & 2,338 & $0,0 \%$ \\
cabc & 862 & $-0,2 \%$ & ciec & 2,164 & $0,0 \%$ \\
sdcc & 1,268 & $-0,1 \%$ & sdsc & 532 & $0,0 \%$ \\
boab & 2,447 & $-0,1 \%$ & sogc & 1,897 & $0,0 \%$ \\
ttlc & 1,214 & $-0,1 \%$ & sibc & 766 & $0,0 \%$ \\
stbc & 1,628 & $-0,1 \%$ & semc & 571 & $0,0 \%$ \\
shec & 1,725 & $-0,1 \%$ & bnbc & 887 & $0,2 \%$ \\
snts & 1,723 & $-0,1 \%$ & prsc & 388 & $0,5 \%$ \\
\hline
\end{tabular}

Tables 2 and 3 allow us to see that the average individual profitability during the given time varies respectively from $4 \%$ to $31 \%$ for the passive strategy and $-0.6 \%$ to $0.5 \%$ for the active strategy. The number of days of transactions (observations) differs from one share to the other, as is shown in Table 3. From that table, we notice that some shares are more dynamic or more traded than others. This certifies to the scarcity of certain shares and predicts that they will 
be stationary. We note that the companies whose shares are the least traded are those with a positive non-zero profitability. Most stocks have negative profitability. They concern 10 shares in the sample, the rest of the shares have zero profitability except for the last two (2) shares.

\subsection{Volatility of the Profitability}

The optimality of a portfolio depends not only on its maximum profitability but also on the price volatility of the prices of assets that it is composed of. This means that we have to assess each strategy in terms of profitability, but also in terms of the degree of volatility. Depending on relation [11], table 4 shows the volatility of each portfolio for the active strategy and for the passive strategy.

It is important to remember that volatility reflects the degree of fluctuation in the value of any asset around a central trend. It is measured from the time variations in the profitability of an asset, following movements or shocks that the market suffered. This risk is estimated by the coefficient of variation (CV) in absolute value. This coefficient reflects the deviation of the average profitability of each management strategy from zero.

Table 4. Volatility of the portfolios for the passive strategy and for the dynamic strategy

\begin{tabular}{|c|c|c|c|c|c|c|c|}
\hline \multirow{2}{*}{ Element } & \multicolumn{3}{|c|}{ Passive strategy $\left(\mathrm{S}_{\mathbf{j}}\right)$} & \multicolumn{3}{|c|}{ Active strategy $\left(S_{k}\right)$} & \multirow{2}{*}{ Deviation } \\
\hline & $\mathbf{r}\left(\mathbf{s}_{\mathbf{j}}\right)$ & $\mathbf{S}$ & $\mathrm{CV}$ & $\mathbf{r}\left(\mathbf{s}_{\mathbf{k}}\right)$ & $\mathbf{S}$ & $\mathrm{CV}$ & \\
\hline Result & 0,11810 & 0,11667 & 0,11525 & 0,00079 & 0,00437 & 5,51380 & 5,39854 \\
\hline
\end{tabular}

We can see from Table 4 that the dispersion of the passive strategy portfolio tends towards zero. This indicates a lower level of volatility for the passive strategy (0.11) than in dynamic strategy (5.51) with a very significant difference (5.39). This difference shows the degree of importance of the deviation of the dynamic portfolio compared to that of the passive portfolio.

\subsection{Study of the Stationarity of Profitability}

Because of the controversial empirical results on the normality of the stock market data mentioned above, we will get rid of the test of the profitability normality in order to present only the development of the daily profitability observed on the Regional Stock Exchange and the stationarity test.

\subsubsection{The Development of the Profitability}

The graph below highlights the daily evolution of the profitability of shares on the regional stock exchange. We can observe that the returns are characterized by asymmetrical and irregular movements as noted respectively by Escribano et al (1997) and Teräsvirta and Anderson (1992). This asymmetry obviously shows an abnormal distribution of profitability.

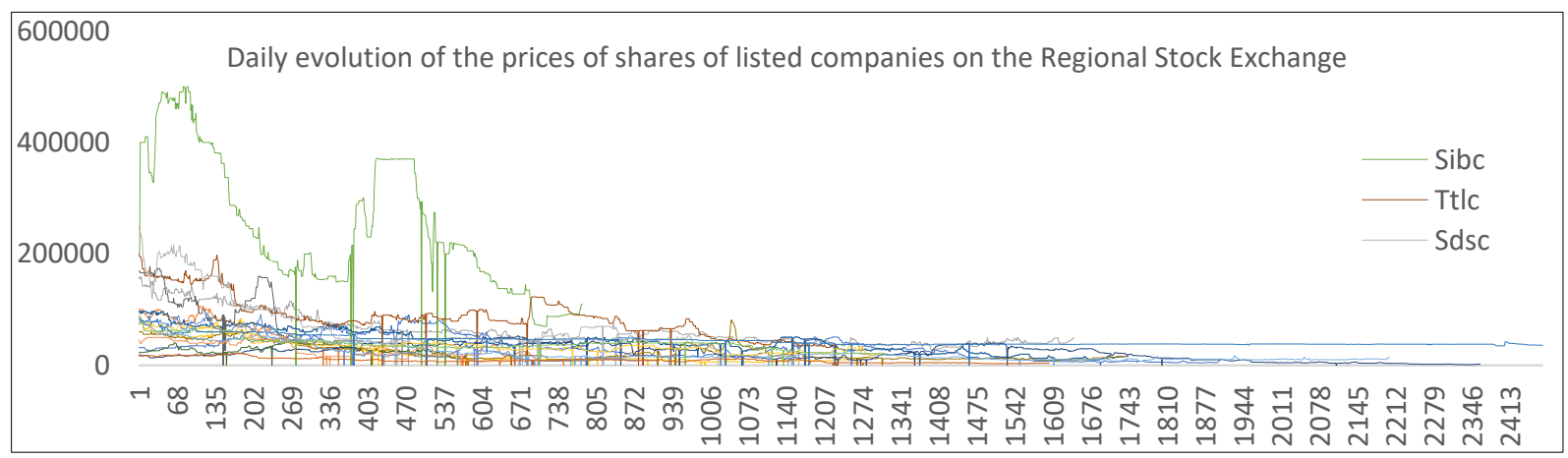

Except for these shares (sibs, sdsc and ttlc) we can observe an almost stable evolution of the prices of shares on the Regional Stock Exchange. This stability suggests a possibility of predicting tomorrow's price based on today's price.

4.3.2 Stationarity of the Profitability

Table 5 shows the results of the test of Dickey-Fuller. The results of the test show that all the daily profitability are stationary in the time with a threshold of $1 \%$ and $10 \%$. This appears to be a sign of stability of the market. 
Table 5. Dickey-Fuller test for unit root

\begin{tabular}{|l|c|c|c|l|c|c|c|}
\hline Companies & Coef. $\boldsymbol{\varphi}$ & $\boldsymbol{T}$. Stat & Observations & Companies & Coef. $\boldsymbol{\varphi}$ & T.Stat & Observations \\
\hline Sgbc & -1.25255 & -23.818 & Stationary & Sphc & -.91485 & -28.165 & Stationary \\
Cabc & -1.17025 & -33.697 & Stationary & Semc & -.89094 & -20.959 & Stationary \\
Stbc & -1.01026 & -19.986 & Stationary & Ciec & -1.11811 & -33.917 & Stationary \\
Sdcc & -.950234 & -19.875 & Stationary & Cfac & -.76595 & -13.999 & Stationary \\
Sogc & -.925392 & -28.451 & Stationary & Sdsc & -.998322 & -30.381 & Stationary \\
Sibc & -.907725 & -25.024 & Stationary & Bicc & -.994762 & -30.274 & Stationary \\
Snts & -1.19337 & -37.114 & Stationary & Bnbc & -1.04525 & -31.074 & Stationary \\
Ttlc & -.913712 & -27.855 & Stationary & Boan & -1.22123 & -16.756 & Stationary \\
Prsc & -1.42317 & -31.652 & Stationary & Boab & -1.37192 & -24.473 & Stationary \\
Shec & -.865802 & -18.929 & Stationary & Sicv & -1.23948 & -31.726 & Stationary \\
\hline
\end{tabular}

We can observe that the statistics of Dickey-Fuller is always lower than the critical values. The zero hypothesis is therefore rejected for all the shares studied. As a consequence, the series of daily profitability are all stationary. This stationarity of the daily profitability is not at all surprising, as is testified by a good number of empirical works in this sense.

\section{Discussion of the Results}

Our results teach us, with regard to the values obtained and their significance, that the distribution of daily returns deviates from the normal distribution on the one hand, but is stable and stationary on the other hand. This suggests that tomorrow's price is predictable from that of today. As a result, betting on the variations of prices is therefore not useful in obtaining economic benefits due to the lack of significant fluctuation in daily prices. This lack of fluctuation is a sign of an inefficient market. Because the instantaneous integration of information in the sense of market efficiency cannot be possible on emerging markets, especially since the speed at which a country's stock exchange integrates information depends on the level of economic development of this country (De Brouwer and Smiles, 2002). In this sense, this means to consider that developed countries with developed stock exchanges integrate information more quickly (Stachowiak, 2004). Practitioners should therefore be careful when betting on these types of markets, because having information is not enough to react, if the investors are holding their shares.

Furthermore, the results also revealed that the average profitability derived from price changes over the study period is generally negative. These results join those of Essingone and Diallo, (2019). If an investor had invested in these assets, he would have lost about $0.43 \%$. We can therefore imagine that the strategy proposed by Shefrin and Statman (2000), and which consists in investing part of one's wealth in low-risk assets and the remaining part in other non-risky assets, is not beneficial. Because, the results indicate that diversifying the portfolio with several assets penalizes the investor by increasing the level of volatility to a generally negative profitability. We observe that the volatility level of the dynamic strategy and the passive strategy is respectively 5.51 and 0.11 in relation to zero. In addition to penalizing the investor, the dynamic portfolio is more dispersed than that of the passive portfolio of 5.39. Like Lapointe (2011), we can consider that individual returns are more homogeneous in passive strategy than in dynamic strategy. We can therefore deduce that the buy and hold strategy is better than the dynamic or active strategy. This is one of the reasons that justify the logic of retention of shares by the portfolio managers highlighted in the work of Bayala and Bama (2019) and Bama and Bayala (2020). However, if it is beneficial for an investor to practice the buy and hold strategy as the practice of this strategy has consequences on market liquidity because, the liquidity of a market is positively correlated with the volume of outstanding shares (Bayala and Bama, 2019). In this configuration, if investors keep the shares for a long term as the buy and hold strategy requires, the number of investors who can participate in the trading of shares is reduced, and consequently the market liquidity will also decrease. Nevertheless, stock exchanges are expected to be in cash. Therefore, one challenge for regulatory authorities is to raise the level of cash flow of their respective stock exchanges. One of the apparent solutions is to strengthen liquidity contracts between issuers and intermediaries.

\section{Conclusion}

The purpose of this applied research has been to focus on the portfolio management in the specific case of the West African regional stock exchange, regarding two management strategies. These are the active strategy and the passive strategy. In this article, we intuitively compared through an empirical study, two investors who are distinguished only by their investment strategy. An investor who is constantly betting on price fluctuations to another who is betting on dividends. Their strategies are labelled respectively as dynamic management strategy and passive management strategy. The approach is inspired by the approach of a simulation method applied to real data from an emerging market. The main results from this study indicate that the regional stock exchange is a savings market more than it is a speculation 
market. Diversifying the portfolio across all of the shares studied penalizes an investor by increasing the level of overall volatility. A rational investor would benefit from anticipating dividends rather than anticipating changes in stock prices. The buy-and-hold strategy therefore proves to be the best for an investor to be rewarded on the market. However, this practice can lead to a general decline in liquidity, especially since liquidity is positively correlated with the volume of outstanding shares. This is a challenge that stock market regulators should meet by strengthening the liquidity contracts between issuers and intermediaries. Furthermore, the hypothesis of non-stationary test is rejected for all the stocks that have been studied. As a result, the daily profitability series are all stationary. This shows that in the case of the West African regional stock exchange, we can predict tomorrow's prices based on today's prices. This result does not mean that investors are making good predictions because the predictability of prices is due to the absence of changes in asset prices on the market. Therefore, it will be difficult for one speculator to outperform the other. Overall, the results of this study advocate for keeping assets. However, due to the small size of our sample and the specificity of the regulatory framework for the West African regional stock exchange, it is advisable that an extension of this analysis be applied to other emerging markets whereby a significant number of companies are listed in order to deepen the results and the best portfolio management strategy.

\section{Acknowledgements}

The author would like to thank two anonymous referees and the editor for their valuable comments in improving the paper.

\section{References}

Aaron, C., Bilon, I., Galanti, S., \& Tadjeddine, Y. (2005). Les styles des gérants d'OPCVM actions françaises en 2003. Revue d'économie financière, 81, 171-188. https://doi.org/10.3406/ecofi.2005.4018

Bama, P. D. D. (2019). Portfolio Managers' Inertia towards published information: The Case of Intermediation Companies on the West African Regional Stock Exchange. African Accounting and Finance Journal, 2, 6-23. https://doi.org/10.1504/AJAAF.2019.10020506

Bama, P. D. D., \& Bayala, B. S. A. (2020). Risque et rentabilité sur un marché boursier émergent : une analyse par la gestion de portefeuille. Revue RAMRES, Série économie et Gestion, 8, 32 - 50.

Bargh, J. A., \& Chartrand, T. L. (1999). The unbearable automaticity of being. American psychologist, 54(7), 462 - 479. https://doi.org/10.1504/AJAAF.2019.099167 https://doi.org/10.1037/0003-066X.54.7.462

Bayala, B. S. A., \& Bama, P. D. D. (2019). Availability of shares on the West Africa regional stock exchange: scarcity or illusion?', African J. Accounting, Auditing and Finance, 6(3), 260-278. https://doi.org/10.1504/AJAAF.2019.099167

Bayala, S. (2002). La bourse régionale des valeurs mobilière, l'introduction en bourse : Pourquoi et pourquoi pas ? Les sociétés et les investisseurs (Thèse de Doctorat) ;

Bayoudh, F., Houfi, M. A., Tissaoui, K., \& Zamouri, S. (2009). Volatilité excessive sur les marchés financiers: essai d'explication par la finance comportementale. Cas de l'excès de confiance sur la Bourse de Tunis », Annales des sciences économiques et de gestion, FSJES Jendouba, 259-297.

Bekaert, G., \& Harvey, C. R. (1995). Time-varying world market integration. The Journal of Finance, 50(2), 403 - 444. https://doi.org/10.2139/ssrn.796189

Bouattour, M., \& Miloudi, A. (2016). Finance comportementale et dynamique des prix des actifs: Une application par la méthode expérimentale. Recherches en Sciences de Gestion, 2, 113-136. https://doi.org/10.3917/resg.113.0113

Boudon, R. (1998). Au-delà du modèle du choix rationnel ? In Les modèles de l'action, Presses Universitaires de France. https://doi.org/10.3917/puf.saint.1998.01.0021

Bourachnikova, O. (2009). La théorie comportementale du portefeuille vs le modèle moyenne-variance. Etude empirique (No. 2009-12). Laboratoire de Recherche en Gestion et Economie (LaRGE), Université de Strasbourg ;

Boyer, M., Cherkaoui, M., \& Ghysels, E. (1997). L'intégration des marchés émergents et la modélisation des rendements des actifs risqués: une étude appliquée à la bourse des valeurs de Casablanca. L'Actualité économique, 73(1-2-3), 311-330. https://doi.org/10.7202/602230ar

Chordia, T., Roll, R., \& Subrahmanyam, A. (2005). Evidence on the speed of convergence to market efficiency. Journal of Financial Economics, 76(2), 271-292. https://doi.org/10.1016/j.jfineco.2004.06.004

Christol, M. (1996). Notes d'épigraphie. Cahiers du Centre Gustave Glotz, 7, 307-318. https://doi.org/10.3406/ccgg.1996.1417 
Davis, J. P., Eisenhardt, K. M., \& Bingham, C. B. (2007). Developing theory through simulation methods. Academy of Management Review, 32(2), 480-499. https://doi.org/10.5465/amr.2007.24351453

De Brouwer, G., \& Smiles, S. (2002). Are East Asian Financial Markets Different? A look at Equity Markets, working paper. https://doi.org/10.1162/REST_a_00167

De Winne, R., \& D'Hondt, C. (2017). La finance comportementale: enjeux et perspectives. Regards économiques 1.

Enowbi, M. B., Guidi, F., \& Mlambo, K. (2010). Testing the weak-form market efficiency and the day of the week effects of some African countries. African Finance Journal, (Special issue 1), 1-26. https://hdl.handle.net/10520/EJC33729

Escribano, A. (2004). Nonlinear error correction: The case of money demand in the United Kingdom (1878-2000). Macroeconomic Dynamics, 8(1), 76-116. https://doi.org/10.1017/S1365100503030013

Essingone, H. N., \& Diallo, M. S. (2018). Risk and Return: The Case of Securities Listed on the West African Economic and Monetary Union Regional Exchange of Securities (BRVM). Applied Economics and Finance, 6(1), 97-108. https://doi.org/10.11114/aef.v6i1.3778

Fama, E. F. (1970). Efficient capital markets: A review of theory and empirical work. The journal of Finance, 25(2), 383-417. https://doi.org/10.2307/2325486

Fama, E. F., \& French, K. R. (1992). The cross-section of expected stock returns. The Journal of Finance, 47(2), 427-465. https://doi.org/10.1111/j.1540-6261.1992.tb04398.x

Goh, K. L., \& Kok, K. L. (2001). Forecasting the intraday Kuala Lumpur Stock Exchange Composite Index. Faculty of Economics \& Administration, University of Malaya.

Gouin, R., \& Harguindéguy, J. B. (2009). Retour de la rationalité limitée et cognition forte: enjeux et intérêts pour le renouvellement de l'analyse des politiques publiques. » In 10e Congrès de l'ASFP, section 39: Les mobilisations ethnolinguistiques en Europe, axe 1: Les concepts et les approches: flux et reflux.

Hatemi-J, A. (2002). Money supply and the informational efficiency of the stock market in Korea: evidence from an alternative methodology. Journal of Economic Integration, 17(3), 517-526. https://doi.org/10.11130/jei.2002.17.3.517

Hirshleifer, D. (2001). Investor psychology and asset pricing. The Journal of Finance, 56(4), 1533-1597. https://doi.org/10.1111/0022-1082.00379

Hua, F., \& Wang, J. (2018). How Investor Sentiment Impacts Financial Decision-making Behavior: From A Cognitive Neuroscience Perspective. NeuroQuantology, 16(5), 567-573. https://doi.org/10.14704/nq.2018.16.5.1385

Jeffery, M., \& Leliveld, I. (2004). Best practices in IT portfolio management. MIT Sloan Management Review, 45(3), 41-49.

Kryzanowski, L., \& Liu, F. (1997). Intraday Predictability of Market Microstructure Statistics and Technical Trading Rules. Centre for Research in Financial Services, School of Accountancy and Business, Nanyang Technological University.

Kyrtsou, C., \& Terraza, M. (2003). Is it possible to study chaotic and ARCH behaviour jointly? Application of a noisy Mackey-Glass equation with heteroskedastic errors to the Paris Stock Exchange returns series. Computational Economics, 21, 57-276. https://doi.org/10.1023/A:1023939610962

Lakonishok, J., Shleifer, A., \& Vishny, R. W. (1992). The impact of institutional trading on stock prices. Journal of financial economics, 2(1), 23-43. https://doi.org/10.1016/0304-405X(92)90023-Q

Langer, E. J. (1989). Minding matters: The consequences of mindlessness-mindfulness. In Advances in experimental social psychology, 22, 137-173. https://doi.org/10.1016/S0065-2601(08)60307-X

Lapointe, J. J. (2011). Conduite d'une étude de besoins en éducation et en formation: Une approche systémique, 256.

Lecourt, C. (2000). Dépendance de court et de long terme des rendements de taux de change. Économie \& prévision, 5(146), 127-137. https://doi.org/10.3406/ecop.2000.6132

Loewenstein, G. (2001). The creative destruction of decision research. Journal of Consumer Research, 28(3), 499-505. https://doi.org/10.1086/323738

Louis, M. R., \& Sutton, R. I. (1991). Switching cognitive gears: From habits of mind to active thinking. Human relations, 44(1), 55-76. https://doi.org/10.1177/001872679104400104

Markowitz, H. (1952). Portfolio selection. The journal of finance, 7, 77-91. https://doi.org/10.1111/j.1540-6261.1952.tb01525.x 
Markowitz, H. (1959). Portfolio Selection, Efficent Diversification of Investments. J. Wiley.

Mathis J. (2002). Gestion d'actifs, Économica, Gestion.

Mlambo, C., \& Biekpe, N. (2007). The efficient market hypothesis: Evidence from ten African stock markets. Investment Analysts Journal, 36(66), 5-17. https://doi.org/10.1080/10293523.2007.11082489

N'dong, B. (2007). Marchés boursiers émergents et problématique de l'efficience : le cas de la Bourse Régionale des Valeurs Mobilières (BRVM)» (Doctoral dissertation, Besançon).

N'dri L, K. (2007). Prévisibilité des rentabilités boursières: cas de la BRVM. African Review of Money Finance and Banking, 39-54. https://www.jstor.org/stable/41410525

Orléan, A. (2001). Comprendre les foules spéculatives: mimétismes informationnel, autoréférentiel et normatif. Crises financières, Economica, Paris.

Petit, E. (2011). L'apport de la psychologie sociale à l'analyse économique. Revue d'économie politique, 121(6), 797-837. https://doi.org/10.3917/redp.216.0797

Sharpe, W. F. (1964). Capital asset prices: A theory of market equilibrium under conditions of risk. The journal of finance, 19(3), 425-442. https://doi.org/10.1111/j.1540-6261.1964.tb02865.x

Sharpe, W. F. (1992). Asset allocation: Management style and performance measurement. Journal of portfolio Management, 18(2), 7-19. https://doi.org/10.3905/jpm.1992.409394

Shefrin, H., \& Statman, M. (2000). Behavioral portfolio theory. Journal of financial and quantitative analysis, 35(2), 127-151. https://doi.org/10.2307/2676187

Shiffrin, R. M., \& Schneider, W. (1977). Controlled and automatic human information processing: II. Perceptual learning, automatic attending and a general theory. Psychological review, 84(2), 127-190. https://doi.org/10.1037/0033-295X.84.2.127

Shiller, R. C. (2000). Irrational exuberance. Philosophy \& Public Policy Quarterly, 20(1), 18-23.

Simon, H. A. (1955). A behavioral model of rational choice. The quarterly journal of economics, 69(1), 99-118. https://doi.org/10.2307/1884852

Stachowiak, C. (2004). Prévisibilité des rentabilités boursières. Economie \& prévision, 5(166), 71-85. https://doi.org/10.3917/ecop.166.0071

Stiglitz, J. E., \& Weiss, A. (1981). Credit rationing in markets with imperfect information. The American economic review, 71(3), 393-410. https://www.jstor.org/stable/1802787

Teräsvirta, T., \& Anderson H. M. (1992). Characterizing Nonlinearities in Business Cycles using Smooth Transition Autoregressive Models, in Nonlinear Dynamics, Chaos and Econometrics, Edited by Pesaran M.H.and Potter S.M., 7(51), 111-128. https://doi.org/10.1002/jae.3950070509

Thaler, A., \& Sunstein, C. (2009). Nudge: Improving Decisions About Health, Wealth, and Happiness, Penguin Books;

Thaler, R. (1980). Toward a positive theory of consumer choice. Journal of economic behavior \& organization, 1(1), 39-60. https://doi.org/10.1016/0167-2681(80)90051-7

Tversky, A., \& Kahneman, D. (1974). Judgment under uncertainty. Heuristics and biases Science, 185(1457), 124-1131. https://doi.org/10.1126/science.185.4157.1124

\section{Copyrights}

Copyright for this article is retained by the author(s), with first publication rights granted to the journal.

This is an open-access article distributed under the terms and conditions of the Creative Commons Attribution license which permits unrestricted use, distribution, and reproduction in any medium, provided the original work is properly cited. 